\title{
Fall in immune complex levels during gold treatment of rheumatoid arthritis
}

J. HIGHTON, G. S. PANAYI, P. SHEPHERD, *A. FAITH, J. GRIFFIN, AND T. GIBSON

From the Departments of Medicine and Rheumatology, Guy's Hospital Medical School, and the *Department of Chemical Pathology, Guy's Hospital Medical School, London Bridge, London SE1 9RT

SUMMARY Prior to starting gold treatment 30 patients with rheumatoid arthritis had an elevated mean level of circulating immune complexes measured by $\mathrm{Clq}$ binding activity. Gold treatment led to an improvement in disease reflected by significant falls in erythrocyte sedimentation rate $(\mathrm{p}<0.001)$, C-reactive protein $(\mathrm{p}<0.01)$, Ritchie articular index $(\mathrm{p}<0.001)$, and duration of morning stiffness $(p<0 \cdot 05)$. Concurrently immune complex levels fell, and this change first reached significance after 3 months' treatment $(\mathrm{p}<0.05)$. Serum $\mathrm{Clq}$ binding activity was not related to clinical and laboratory measurements of joint inflammation. This suggested to us that there is no direct immunopathological relationship between circulating immune complexes and joint inflammation in rheumatoid arthritis. Serum $\mathrm{Clq}$ binding activity was strongly related to IgM-RF levels measured as latex titre $(r=0.7, p<0.001)$. Removal of immune complexes from serum with Sepharose 4B-staph A (staphylococcal protein A) led to a fall in IgM-RF from $2 \mathrm{mg} / \mathrm{ml}(2 \mathrm{~g} / \mathrm{l})$ to $0.4 \mathrm{mg} / \mathrm{ml}(0.4 \mathrm{~g} / \mathrm{l})$. This suggests that the reason for the relationship between $\mathrm{Clq} \mathrm{BA}$ and IgM-RF is that, on average, $80 \%$ of serum IgM-RF exists as part of immune complexes containing IgG.

Numerous studies have documented the presence of raised levels of immune complexes in patients with rheumatoid arthritis, and some authors have suggested that they may be related to the aetiology of the disease. ${ }^{1}$ Fewer investigations have been made into the change in levels of immune complexes during effective treatment of rheumatoid arthritis. This might be expected to yield useful information on the temporal relationship between changes in immune complex levels and joint inflammation. If immune complexes are aetiologically related to joint inflammation, circulating levels might be expected to fall prior to or at the same time as improvement in joint inflammation. It also seemed to us that the period following initiation of gold therapy in which disease activity was changing most rapidly would be a particularly good time in which to study the relationship between clinical and serological measurement of disease activity and levels of circulating immune complexes.

Accepted for publication 16 December 1980.

Correspondence to Dr J. Highton, Wellcome Research Institute, Frederick Street, Dunedin, New Zealand.

\section{Materials and methods}

Thirty patients with definite or classical rheumatoid arthritis ${ }^{2}$ were studied. These were 23 females and 7 males, mean age 58.4 years (range $34-76$ ). Twentyfour were seropositive and 6 persistently seronegative for rheumatoid factor. Disease duration ranged from 1 to 48 years, mean $7 \cdot 6$.

\section{PATIENT ASSESSMENT}

All patients were treated with intramuscular sodium aurothiomalate (GST), 16 in a high dose schedule and 14 in a low dose schedule. The high dose group received $50 \mathrm{mg}$ GST weekly to a total dose of $1 \mathrm{~g}$ and then $50 \mathrm{mg}$ monthly; the low dose group $10 \mathrm{mg}$ GST to a total of $200 \mathrm{mg}$ and then $20 \mathrm{mg}$ monthly. Each patient was assessed monthly by the same observer, who measured Ritchie articular index, ${ }^{3}$ grip strength in $\mathrm{mmHg}$ using a modified sphygmomanometer cuff, time in seconds to walk $10 \mathrm{~m}$, total proximal interphalangeal joint circumference in $\mathrm{mm}$, and duration of morning stiffness in minutes. Blood was taken at the time of each assessment for measurement of erythrocyte sedimentation rate 
(ESR, Westergren), C-reactive protein (CRP), rheumatoid factor (IgM-RF) as latex titre, and $\mathrm{Clq}$ binding activity ( $\mathrm{Clq} \mathrm{BA}$ ) as a measure of immune complexes. Observations were started immediately before the initiation of gold therapy. Mean follow-up was 8 months, range 4 to 12 months.

\section{C-REACTIVE PROTEIN LEVELS}

CRP levels were measured by single radial immunodiffusion in $1 \%$ agar in phosphate buffered saline, pH $7 \cdot 2$, containing $1 \%$ rabbit anti-CRP (Behringwerke).

\section{LATEX TITRE}

IgM-RF levels were measured by latex agglutination in tubes ${ }^{4}$ with sera stored at $-20^{\circ} \mathrm{C}$. To avoid within-patient variation all sera relating to a particular individual were assayed in the same batch. Known positive and negative sera were included in each assay as controls. Results were expressed as the reciprocal of the serum dilution in the most dilute positive tube. Results of 80 or above were regarded as positive for RF.

THE ${ }^{125}$ I C $1 Q$ BINDING ASSAY

The C1q subcomponent of complement was isolated from pooled normal human serum by the method of Reid et al..$^{5}$ and radioiodinated with chloramine $\mathrm{T}$ to a specific activity ranging from 0.4 to $0.8 \mu \mathrm{Ci} / \mu \mathrm{g}$ $\mathrm{Clq}^{6}$ The ${ }^{125} \mathrm{I} \mathrm{Clq}$ binding test was performed as described by Zubler et al. ${ }^{7}$ Before they were tested the sera were stored at $-70^{\circ} \mathrm{C}$ and were then estimated in batches, so that all sera from each individual patient were included in the same batch. Results were expressed as percentage ${ }^{125} \mathrm{I}$ Clq bound.

\section{ABSORPTION OF RHEUMATOID SERA WITH SEPHAROSE 4B-STAPH A PROTEIN}

Fourteen rheumatoid sera were absorbed with staphylococcal protein A (staph A) conjugated to Sepharose 4B (Pharmacia) to remove IgG-containing immune complexes. Sepharose 4B-staph A was extensively washed and an equal quantity $(0.2 \mathrm{ml})$ aliquoted into $2.5 \mathrm{ml}$ plastic tubes (Luckhams PTO944) and $0.6 \mathrm{ml}$ serum added. Tubes were rotated overnight at $4^{\circ} \mathrm{C}$. The sera were then spun twice to remove Sepharose and stored at $-70^{\circ} \mathrm{C}$ prior to estimation of $\mathrm{Clq}$ binding activity and IgM-RF. An exactly similar procedure was carried out with unconjugated Sepharose 4B (Pharmacia) as a control.

QUANTITATIVE MEASUREMENT OF

IgM RHEUMATOID FACTOR IN ABSORBED SERA Levels of IgM-RF in absorbed sera were measured by an enzyme-linked immunosorbent assay (ELISA).
This assay will be described in detail in a subsequent publication. Briefly, $100 \mu \mathrm{l}$ DE-52 purified human $\operatorname{IgG}(7 \mu \mathrm{g} / \mathrm{ml})$ is added to each well of a microtitre plate and allowed to react overnight at room temperature. Test sera are diluted $1 / 100$ and $100 \mu \mathrm{l}$ added to wells in duplicate and again reacted overnight at room temperature. $100 \mu \mathrm{l}$ of alkaline phosphatase conjugated goat antihuman 1gM (Miles Yeda) at 1 in 500 dilution is then added to each well for 2 hours. Enzyme substrate is made by dissolving 1 tablet of Sigma phosphatase substrate 104 per

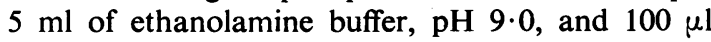
added to each well. The reaction is stopped after 10 minutes by adding an equal quantity of $3 \mathbf{M}$ sodium hydroxide. Results are read as absorbance at 405 nanometers with a Beckman Micro-elisa minireader.

Serial dilutions of a known seropositive serum are included as a standard. The amount of IgM-RF in the standard has been previously estimated by absorption of the IgM-RF with aggregated IgG followed by measurement of serum IgM before and after absorption by single radial immunodiffusion. A standard curve is constructed from the readings from the serial dilutions of this standard serum and results read as $\mu \mathrm{g}$ IgM-RF per ml.

\section{EVALUATION OF RESULTS}

Changes in each parameter over the period of observations were examined for significance by analysis of variance on a computer program (Statistical Package for the Social Sciences, SPSS). Mean values for each month were compared with the initial values by means of an unpaired Student's $t$ test. Unpaired testing was used because the length of follow-up varied, so that pairing was not possible.

Correlations between the parameters measured were evaluated by linear regression on an SPSS program. Because of the large number of observations made (170-230), $r$ values as low as 0.15 were statistically significant. This level of correlation obviously has no meaning, and compensation for the large number of individual observations and the large nurnbers of parameters correlated (9) was therefore made by selecting an $r$ value of 0.4 or greater as being meaningful.

\section{Results}

At the beginning of treatment this group of patients with rheumatoid arthritis had active disease; mean ESR was $46 \mathrm{~mm} / \mathrm{h}$, CRP $40 \mu \mathrm{g} / \mathrm{ml}(40 \mathrm{mg} / \mathrm{l})$, Ritchie articular index (RI) $9 \cdot 5$, and duration of morning stiffness (DMS) 60 minutes. During gold treatment there was an improvement in disease activity. This was reflecte 1 by significant falls in 
$\operatorname{ESR}(p<0.001), \operatorname{CRP}(p<0.01), \operatorname{RI}(p<0.001)$, and DMS $(\mathrm{p}<0.05)$. There was also a fall in mean latex titre from 8300 to 2500 , but this was not statistically significant. Changes in grip strength, walking time, and total proximal interphalangeal (PIP) joint size were not significant.

At the time of maximum disease activity before the start of gold treatment patients had raised levels of circulating immune complexes. Mean Clq BA was $34 \%$, which is approximately twice the upper limit of normal (mean $+2 \mathrm{SD}=15 \%$ ). Individual levels ranged from 4.8 to $70 \cdot 1 \%$. During treatment there was a fall in immune complex levels which was

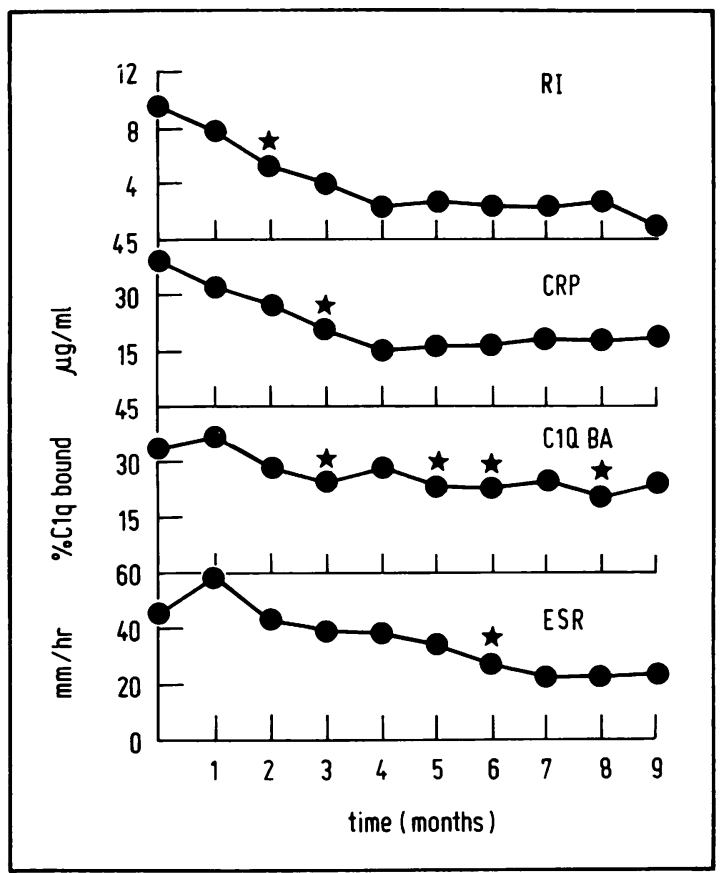

Fig. 1 Differences in the time and extent of falls in serum immune complex levels and measurements reflecting inflammatory disease activity during gold treatment of rheumatoid arthritis. Immune complex levels measured as $\mathrm{Clq}$ binding activity $(\mathrm{Clq} B A)$ fall initially and then plateau. The fall is first significant after 3 months of gold treatment $(p=0.04)$ by unpaired Student's t test. Levels at 5 months $(p=0.03), 6$ months $(p=0.02)$, and 8 months $(p=0.01)$ are also significantly less than the starting value (indicated by stars). The falls in Ritchie articular index $(R I)$ and $C$-reactive protein $(C R P)$ reach significance at 2 months $(p=0.03)$ and 3 months $(p=0.003)$ of gold treatment respectively (indicated by stars). At 4 months $p<0.001$ for both of these measurements. ESR falls steadily to reach significance at 6 months $(p=0.007)$. statistically significant by analysis of variance $(\mathrm{p}<0 \cdot 01)$.

PATTERN OF FALL IN DISEASE MEASUREMENTS In a comparison of mean levels of immune complexes for each successive month of treatment with initial values by unpaired Student's $t$ test the fall in immune complex levels first reached significance at 3 months (Fig. 1). However, the level at 4 months was not significantly different from the initial value. Levels were more consistently lowered from 5 months onwards, but even then the levels at 7 and 9 months were not significantly lower than initial values.

This reflects the rather small quantitative change in immune complex levels and the fact that they plateau at levels at the limit of significance. This pattern differs from the steeper and more sustained falls in RI and CRP. The fall in these measurements first reached significance at 2 and 3 months respectively. After this they fell further and reached a plateau at levels consistently significantly different from their starting values $(p<0.001$ at 4 months for both measurements). These differences are clearly seen in Fig. 1.

\section{CORRELATIONS BETWEEN}

DISEASE MEASUREMENTS

Table 1 shows the correlation between measurements which showed significant falls during treatment as well as latex titre. In general, these correlations fell into 2 groups. The first group consisted of serologic and clinical measurements reflecting joint inflammation, namely, ESR, CRP, RI, and DMS. ESR and CRP were strongly related and both correlate with the clinical measurements to a similar degree.

The second group consisted of $\mathrm{Clq}$ BA and latex titre. These 2 measurements were strongly related $(\mathrm{r}=0.7, \mathrm{p} \ll 0.001)$. Latex titre correlated with DMS ( $\mathrm{r}=0.41, \mathrm{p}<0.001)$, but Clq BA was only weakly related to measurements of disease activity (Table 1).

\section{RELATIONSHIP BETWEEN C $1 Q$ BINDING}

ACTIVITY AND IgM RHEUMATOID FACTOR

In order to study the strong relationship between IgM-RF measured as latex titre and Clq BA we absorbed 14 rheumatoid sera with staph $A$ to remove IgG containing immune complexes. On analysis 6 sera had $\mathrm{Clq}$ BA $>15 \%$ after absorption with Sepharose 4B (46\% $\pm 7 \%$ mean \pm SEM). C1q BA fell significantly ( $\mathrm{p}<0.001$, paired Student's $t$ test) with staph A absorption to $13.7 \% \pm 3.5 \%$ (mean \pm SEM) which is within the normal range (Fig. 2). There was a corresponding $80 \%$ fall in the 
Table 1 Correlation between clinical and serological measurements made in 30 patients with rheumatoid arthritis during gold treatment

\begin{tabular}{lllll}
\hline & $E S R$ & $C R P$ & $R F$ & $C I q B A$ \\
\hline CRP & $0.66^{*}$ & & & \\
RF & 0.09 & 0.03 & & \\
Clq BA & 0.23 & 0.09 & $0.7^{*}$ & \\
RI & $0.42 \dagger$ & $0.46 \dagger$ & 0.36 & 0.23 \\
DMS & $0.46 \dagger$ & $0.44 \dagger$ & $0.41 \dagger$ & 0.28 \\
\hline
\end{tabular}

Serial measurements of erythrocyte sedimentation rate (ESR), Creactive protein (CRP), IgM rheumatoid factor by latex titre (RF), Clq binding activity (Clq BA), Ritchie articular index (RI), and duration of morning stiffness (DMS) were made monthly in 30 patients with rheumatoid arthritis. The figure shows correlations between measurements as $\mathbf{r}$ values derived by linear regression. To correct for the large number of correlations made an $r$ value of 0.4 was taken to represent a meaningful relationship, indicated by * $(p<0.001)$. The 2 highest correlations are shown by $\dagger(p<0.001)$.

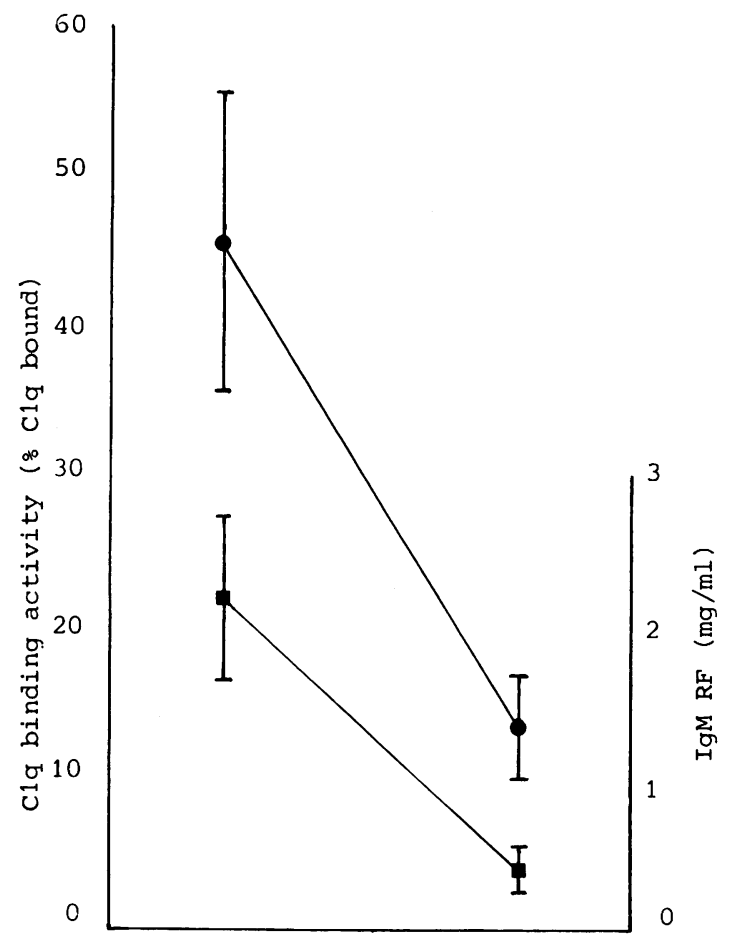

Sepharose 4B Sepharose 4B - Staph A Absorption absorption

Fig. 2 Absorption of immune complexes with Staph $A$ protein leads to a significant fall in serum IgM rheumatoid factor. This figure shows mean levels $( \pm$ standard error of the mean) of Clq binding activity $(\bullet)$ and IgM rheumatoid factor $(\square)$ for 6 rheumatoid sera absorbed with sepharose $4 B$ or staphyloccal protein $A$ (staph $A$ ) linked to sepharose $4 B$. Absorption of sera with staph $A$ produced a significant fall ( $p<0.001$ paired Student's t test) in serum Clq binding activity. Concomitantly there was a significant fall in IgM rheumatoid factor levels $(p<0.05)$. mean level of IgM-RF measured by ELISA from $2 \mathrm{mg} / \mathrm{ml}$ to $0.4 \mathrm{mg} / \mathrm{ml}(2$ to $0.4 \mathrm{~g} / \mathrm{l})(\mathrm{p}<0.05)$. Individual falls varied from $39 \%$ to $97 \%$ of the control absorbed value. The 8 sera with no immune complexes in control sera showed no significant change in C1q BA or IgM RF (data not shown).

\section{Discussion}

We have shown that immune complex levels measured as C1q BA fell significantly as disease activity improved during the early phase of gold treatment. This is in agreement with Nineham et al. ${ }^{8}$ who also showed a fall in C1q binding immune complexes during gold treatment of rheumatoid arthritis but using a solid-phase technique. Falls in immune complex levels have also been reported during penicillamine therapy ${ }^{9}$ and during the treatment of rheumatoid vasculitis with cytotoxic agents. ${ }^{10}$ It would thus seem that effective treatment of rheumatoid arthritis with 'second-line' agents is associated with a fall in levels of circulating immune complexes.

The fall in levels of immune complexes first becomes significant after there is already evidence of clinical improvement in joint inflammation (RI, Fig. 1). The fall in immune complex levels is neither as steep nor as sustained as the falls in RI and CRP, which are generally thought to be good indicators of inflammatory disease activity. These differences favour the concept that circulating immune complex levels are a secondary phenomenon rather than being directly linked to inflammation in joints in rheumatoid arthritis.

If immune complexes were of aetiological significance in the pathogenesis of joint inflammation, one might expect to see a correlation between levels of complexes and clinical and serological measurements of joint inflammation. We did not find evidence for such a relationship (Table 1). This does not preclude an aetiological role for immune complexes in joint inflammation. Firstly, we might be measuring the wrong type of immune complexes, as it is known that different assays give different results. ${ }^{11-13}$ Secondly, we measured serum immune complexes and not those in synovial fluid.

Some previous authors have shown a relationship between C1q binding immune complexes and some features of rheumatoid arthritis. For example, Halla et al. ${ }^{13}$ found that patients with morning stiffness greater than 2 hours had significantly higher levels of C1q BA than those with morning stiffness less than 2 hours. There was a similar finding in patients with ESRs greater than 50. Others have not found any relationship between serum C1q BA and ESR, ${ }^{14}$ 
or disease stage and functional class. ${ }^{12} 14$ In general, high levels of immune complexes tend to correlate more with extra-articular features of rheumatoid arthritis, either measured as $\mathrm{Clq} \mathrm{BA}^{12-14}$ or using $\mathrm{Clq}$ bound to solid-phase. ${ }^{815}$

We have found a strong relationship between levels of Clq BA and IgM RF. Some previous authors have not found such a relationship. ${ }^{12} 14$ However, Lawley et al. ${ }^{16}$, investigating patients with Sjögren's syndrome, including patients with rheumatoid arthritis, found a highly significant relationship $(\mathrm{r}=0.55, \mathrm{p}<0.0005)$ as did Haslam et al. ${ }^{17}$ in patients with fibrosing alveolitis, with or without rheumatoid arthritis $(\mathrm{r}=0.67, \mathrm{p}<0.001)$.

This strong relationship implies that IgM-RF plays a significant part in the immune complexes measured as $\mathrm{Clq}$ binding activity. We have shown that absorption of sera with staph $\mathbf{A}$ is capable of removing nearly all immune complexes measured by Clq binding activity, suggesting that all these complexes contain IgG. This is in agreement with Zubler et al. ${ }^{14}$, who absorbed with rabbit anti-human IgG and Lawley et al. ${ }^{16}$ using staph A. Concomitantly there is a fall in the mean level of IgM-RF of $80 \%$. If it is assumed that staph A specifically adsorbs IgG this result suggests that on average $80 \%$ of IgM-RF is involved in immune complexes containing IgG.

It is interesting that there was a wide individual variation in the amount of IgM-RF apparently complexed in this way $(39 \%-97 \%)$. This might be due to a difference in the affinity of IgM-RF or variations in the relative quantities of IgG-containing complexes and IgM-RF in the circulation. The variation in the relative levels of IgM-RF and immune complexes in serum is exemplified by 9 patients who at some stage of follow-up were seronegative for IgM-RF but had $\mathrm{Clq}$ binding immune complexes, and 4 patients (including 1 of the above) who were seropositive for IgM-RF but had no circulating immune complexes detected. The fact that both situations could be seen in the same patient on different occasions emphasises the dynamic nature of the relationship.

In conclusion this study suggests that (1) the fall in serum levels of immune complexes measured as C1q binding activity occurs as a secondary phenomenon consequent upon an improvement in disease activity induced by gold; (2) the strong relationship between IgM-RF and C1q BA is due to the fact that a significant proportion of IgM-RF is involved in immune complexes.

The authors acknowledge the help of Dr R. Grahame in allowing us to study some of his patients. We also acknow- ledge the technical assistance of Ms P. Burke in the measurements of $\mathrm{Clq}$ binding activity and Ms L. Griffiths in the serial clinical measurements.

\section{References}

1 Theofilopoulos A N, Dixon F J. The Biology and Detection of Immune Complexes. Adv Immunol 1979; 28: 89-220.

2 Ropes M W, Bennet G A, Cobb S, Jacox R, Jessar R A. Diagnostic criteria for rheumatoid arthritis. Ann Rheum Dis 1959; 18: 49-53.

3 Ritchie D R, Boyle J A, McInnes J M, et al. Clinical Studies with an articular index for the assessment of joint tenderness in patients with rheumatoid arthritis. Q J Med 1968; 37: 393-406.

4 Singer J M. Standardisation of the latex test for rheumatoid arthritis serology. Bull Rheum Dis 1973; 24: 762-9.

5 Reid K B M, Lowe D M, Porter R R. Isolation and characterisation of $\mathrm{Clq}$, a subcomponent of the first component of complement, from human and rabbit sera. Biochem J 1972; 130: 749-63.

6 McConahey P J, Dixon F J. A method of trace iodination of proteins for immunologic studies. Int Arch Allergy 1966; 29: 185-9.

7 Zubler R H, Lange G, Lambert P H, Miescher P A (1976). Detection of immune complexes in unheated sera by a modified ${ }^{125}$ I C1q binding test. J Immunol 1976; 116: 232-5.

8 Nineham L J, Hay F C, Male D K, Roitt I M, Young A, Perumal R. Immune complexes in rheumatoid arthritis: correlations with clinical features and effects of gold. Protides of Biological Fluids 1978; 26: 179-82.

9 Mohammed I, Barraclough D, Holborow E J, Ansell B M. Effect of penicillamine therapy and circulating immune complexes in rheumatoid arthritis. Ann Rheum Dis 1976; 35: 458-62.

10 Abel T, Andrews B S, Cunningham P H, Brunner C, Davis J S IV, Horwitz D A. Rheumatoid vasculitis: effect of cyclophosphamide on the clinical course and levels of circulating immune complexes. Arthritis Rheum $1980 ; 23$ : 646 (abstract).

11 Lambert P H, et al. A WHO collaborative study for the evaluation of eighteen methods for detecting immune complexes in serum. J Clin Lab Immunol 1978; 1 : 1-15.

12 Gupta R C, McDuffie F C, Huston K A, et al. Comparison of 3 immunoassays for immune complexes in rheumatoid arthritis. Arthritis Rheum 1979; 22: 433-9.

13 Halla J T, Volanakis J E, Schrohenloher R E. Immune complexes in rheumatoid arthritis sera and synovial fluids: a comparison of three methods. Arthritis Rheum 1979; 22: 440-7.

14 Zubler R H, Nydegger U, Perrin L H, et al. Circulating and intra-articular immune complexes in patients with rheumatoid arthritis. J Clin Invest 1976; 57: 1308-19.

15 Hay F C, Nineham L J, Perumal R, Roitt I M. Intraarticular and circulating immune complexes and antiglobulins (IgG and IgM) in rheumatoid arthritis: correlation with clinical features. Ann Rheum Dis 1979; 38: 1-7.

16 Lawley T J, Moutsopoulos H M, Katz S I, Theofilopoulos A N, Chused T M, Frank M. Demonstration of circulating immune complexes in Sjögren's syndrome. $J$ Immunol 1979; 123: 1382-7.

17 Haslam P L, Thompson B, Mohammed I, et al. Circulating immune complexes in patients with cryptogenic fibrosing alveolitis. Clin Exp Immunol 1979; 37: 381-90. 